\title{
Consenso da União Internacional de Flebologia (UIP) no Ecodoppler
}

\author{
Sattler C. ${ }^{1}$ \\ ${ }^{1}$ Belo Horizonte - Brasil. \\ E-mail: ccsathler@ig.com.br
}

Sattler, C. 2013. Consenso da União Internacional de Flebologia (UIP) no Ecodoppler, p.41. In: Bastos, Francisco Reis. Anais do V Simpósio Internacional de Flebologia [Blucher Medical Proceedings n.1 v.1]. São Paulo: Blucher, 2014 http://dx.doi.org/10.5151/medpro-flebo-SIF_21
Devido ao fato de o eco-Doppler ter-se tornado o exame de referência de estudo da morfologia e hemodinâmica das veias dos membros inferiores, tornou-se também alvo das atenções da União Internacional de Flebologia (UIP). Essa entidade teve a iniciativa de obter um consenso de especialistas internacionais sobre a metodologia de estudo das veias dos membros inferiores com o eco-Doppler. Tendo promovido uma conferência de consenso, produziu-se, subsequentemente, um documento de consenso.

Os autores convidaram um grupo de especialistas de vários países para participarem no projeto. Todos os participantes tiveram livre acesso ao site da UIP, meio pelo qual puderam preparar um documento provisório para discussão no congresso da UIP realizado em S. Diego USA, em Agosto de 2003. Um novo documento foi veiculado entre todos os participantes para novos comentários, os quais foram adicionados à versão final do documento.

Esse documento foi o produto das recomendações detalhadas dos especialistas sobre a metodologia do exame eco-Doppler, bem como da interpretação das imagens e medições, sugerindo uma metodologia para o estudo completo das veias superficiais e perfurantes dos membros inferiores.

Também foram incluídas recomendações sobre o relatório do exame bem como sobre o treino necessário à sua execução e uma revisão sistemática da literatura publicada sobre a anatomia eco-Doppler das veias superficiais dos membros inferiores.

Sendo assim, as recomendações postuladas pela UIP representam a valiosa sugestão de um significativo contingente de especialistas, os quais chegaram a um acordo sobre a metodologia de exame eco-Doppler do sistema venoso dos membros inferiores.

Palavras-chave: ecodoppler, ultra-som, consenso, doppler. 